\section{University fee changes may deter poor students from studying medicine}

\author{
Susan Mayor London
}

Proposed changes to university fees in England may deter students from low income families from studying medicine.

The Higher Education Bill, presented to parliament last week, will enable different universities to charge variable "top up" tuition fees for degree courses. Different fees can also be charged for different courses. Currently most students pay an upfront fee of £1125 (\$2080; $€ 1630$ ) a year. About $30 \%$ of students from the poorest families are exempt. However, the fee barely covers the real cost of tuition.

From 2006 universities will be able to charge up to a maximum of $£ 3000$ a year in fees, with payment deferred until after students graduate and are earning at least $£ 15000$ a year. The BMA has warned that medical schools would be likely to charge the highest level of fees permitted under the scheme, because of the high demand for places, making it particularly expensive to study medicine.

Daniel Gibbons, deputy chairman of the BMA's medical students committee, said: "Fear of debt will mean that many students, particularly those from working class backgrounds, will decide against studying medicine."

He pointed out that medical students could potentially incur a total debt of up to $£ 18000$ in tuition fees during their six year degree course, in addition to debts accrued for living expenses. The Department of Health currently pays tuition fees of $£ 1125$ each year from the fifth year of a medical degree, but the new bill does not indicate what will happen to this arrangement.

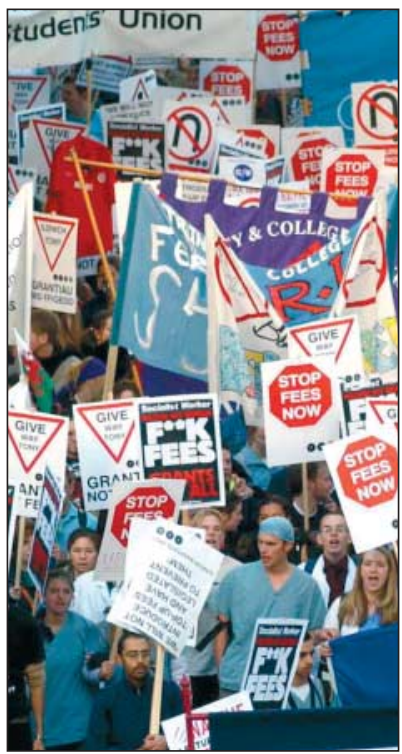

Students demonstrate in central London

The government claimed that top-up tuition fees would provide more income for universities-with further arrangements in the bill aimed at helping the poorest students, by providing at least $£ 3000$ each year for living costs based on parental income. Further arrangements in the bill aim to help the poorest students.

Presenting the recommendations to parliament, Charles Clarke, secretary of state for education and skills, said that the reforms would "protect the poorest students and graduates, help parents of students, and give universities the investment and freedom they need to compete with the best in the world."

He estimated that on average students should expect to pay off their loan in around 13 years. "However, for some it may take longer," he acknowledged.

The BMA warned that the high fees accrued by studying medicine may put some doctors off working for the NHS because of the time it will take them to repay their debt. "With one in four medical graduates already considering not going on to practise medicine, it is likely that many potential doctors will decide against providing a vital public service in favour of something more lucrative," said Mr Gibbons.

Details of the Higher Education Bill can be found at www.dfes.gov.uk

\section{Vasopressin for cardiac arrest increases chances of survival}

\author{
Scott Gottlieb New York
}

People with refractory cardiac arrest are three times as likely to survive if they are given the antidiuretic hormone vasopressin than if they receive the standard emergency treatment, adrenaline (epinephrine).

The new findings are from a study of patients with cardiac arrest in Austria, Germany, and Switzerland.

The current international guidelines for coronary pulmonary resuscitation recommend the use of adrenaline during cardiac resuscitation and consider vasopressin only as a secondary alternative, because clinical data on treatment with vasopressin have been limited.

Researchers led by Volker Wenzel of the department of anaesthesiology and critical care medicine at Leopold-Franzens University, Innsbruck, Austria, randomly assigned adults who had had an out of hospital car- diac arrest to have two injections of either 40 IU of vasopressin or $1 \mathrm{mg}$ of adrenaline, followed by additional treatment with adrenaline if needed. The primary end point was survival to hospital admission, and the secondary end point was survival to hospital discharge (New England Journal of Medicine 2004;350:105-13).

A total of 1186 patients took part in the study: 589 were assigned to receive vasopressin and 597 to receive adrenaline. The two treatment groups had similar clinical profiles.

Among patients with ventricular fibrillation there was no significant difference between the two groups in the percentage of patients who survived to be admitted to hospital $(46.2 \%$ of patients in the vasopressin group and $43.0 \%$ in the adrenaline group; odds ratio $0.9(95 \%$ confidence interval 0.6 to 1.3$)$.
Neither was there a difference among patients with pulseless electrical activity $(33.7 \%$ and $30.5 \%$; odds ratio 0.8 (0.5 to 1.6)).

Among patients with asystole, however, the percentage of patients admitted to hospital was higher in the vasopressin group $(29.0 \%)$ than in the adrenaline group (20.3\%) (odds ratio $0.6(0.4$ to 0.9$))$. The percentage of patients who survived to discharge was also higher in the vasopressin group ( $4.7 \%$ versus $1.5 \%$; odds ratio 0.3 (0.1 to 1.0$))$.

Moreover, among the 732 patients in whom spontaneous circulation was not restored with the two injections of the study drug, additional treatment with adrenaline led to a higher proportion of patients surviving to hospital admission and hospital discharge in the vasopressin group than in the adrenaline group (hospital admission: $25.7 \%$ versus $16.4 \%$; hospital discharge: $6.2 \%$ versus $1.7 \%$ ).

Adrenaline has been used in cardiac pulmonary resuscitation for more than 100 years but has become controversial because it is associated with increased myocardial oxygen consumption, ventricular arrhythmias, and myocardial dysfunction in the period after resuscitation.

Because of the discovery that endogenous vasopressin concentrations were significantly higher in successfully resuscitated patients than in patients who died, it was postulated that administering vasopressin during coronary pulmonary resuscitation might be a benefit.

Laboratory studies showed that vasopressin was associated with better blood flow to vital organs, delivery of cerebral oxygen, chances of resuscitation, and neurological outcomes, compared with adrenaline. But this is the first large scale clinical study to show significant benefits from the use of vasopressin.

Dr Wenzel said he had already changed the way he treated patients. Now he gives nearly all adults with cardiac arrest both vasopressin and adrenaline. "Get it in there, bang bang, and you either save a life immediately or you don't," he said. 